UDC 547.262:621.5.049.2

LBC 35.765

\title{
PROGRESSIVE SCHEMES AND METHODS OF OBTAINING RECTIFIED ALCOHOL APPLIED IN RUSSIA AND ABROAD
}

\author{
Helen A. Oganesyan \\ Volgograd State University, Volgograd, Russian Federation \\ Iulia V. Kolesnichenko \\ Volgograd State University, Volgograd, Russian Federation \\ Galina A. Sroslova \\ Volgograd State University, Volgograd, Russian Federation
}

\begin{abstract}
Annotation. The main quantity of the produced ethyl alcohol is consumed by the food industry as a basis for the manufacture of alcoholic beverages, pharmaceuticals and other alcohol-containing products. In addition to food production, ethyl alcohol is widely used in medicine, perfumery, and other industries. The actual problem of alcohol production is finding ways to reduce the cost of raw materials and energy resources but still getting the world quality standard of alcohol. The best solution to the problem is to improve the technological schemes of rectification plants. For this, information was updated on modern schemes and methods for obtaining rectified alcohol. During the research, and information search was carried out in Russian and English language literary sources. A comparative analysis of books, manuals and articles on this topic was carried out, as well as the GOSTs requirements for rectification columns over the past few years were studied. The main components of rectification units were considered: contact devices (types of plate and packed devices) and rectification columns (applied pressure: atmospheric, vacuum, under a certain pressure; and their total number).Progressive schemes used in modern alcohol production in Russia and abroad (Ukraine, USA, France, Finland) were considered. Based on the received data, the following conclusions were formulated: the most effective types of contact devices are sieve and valve trays, among the packing there are Raschig rings, a promising type of columns is disc-type, the most popular scheme for the operation of a rectification plant is a combination of work under pressure and vacuum.

Key words: alcohol production, alcohol rectification, rectification plant scheme, rectification column, ethyl $\vec{\delta}$ alcohol, rectified alcohol, contact apparatus.

Citation. Oganesyan H.A., Kolesnichenko Iu.V., Sroslova G.A. Progressive Schemes and Methods of Obtaining Rectified Alcohol Applied in Russia and Abroad. Prirodnye sistemy i resursy [Natural Systems and Resources], 2021, vol. 11, no. 2, pp. 66-73. DOI: https://doi.org/10.15688/nsr.jvolsu.2021.2.8

УДК 547.262:621.5.049.2

ББК 35.765
\end{abstract}

ПРОГРЕССИВНЫЕ СХЕМЫ И СПОСОБЫ ПОЛУЧЕНИЯ СПИРТА-РЕКТИФИКАТА, ПРИМЕНЯЕМЫЕ В РОССИИ И ЗА РУБЕЖОМ

\section{Елена Ашотовна Оганесян}

Волгоградский государственный университет, г. Волгоград, Российская Федерация

Юлия Валерьевна Колесниченко

Волгоградский государственный университет, г. Волгоград, Российская Федерация 
Прогрессивные схемы и способы получения спирта-ректификата, применяемые в России и за рубежом

Галина Алексеевна Срослова

Волгоградский государственный университет, г. Волгоград, Российская Федерация

Аннотация. Основное количество произведенного этилового спирта потребляется пищевой промышленностью, где он используется в качестве основы для изготовления ликероводочных, фармацевтических изделий и другой спиртосодержащей продукции. Кроме пищевого производства, этиловый спирт находит широкое применение в медицине, парфюмерии и других отраслях. Актуальная проблема спиртового производства состоит в поиске способов снижении затрат сырья, тепловых и энергетических ресурсов для получения этилового спирта, соответствующего мировому стандарту качества. Оптимальным вариантом решения поставленной проблемы является усовершенствование технологических схем ректификационных установок. Для этого была проведена актуализация информации по современным схемам и способам получения спирта-ректификата. При исследовании был осуществлен биоинформационный поиск в русскоязычных и англоязычных литературных источниках. Был проведен сравнительный анализ книг, пособий и статей по методике получения спирта, а так же изучены нормативные требования ГОСТов для ректификационных установок за последние несколько лет, рассмотрены основные составляющие ректификационных установок: контактные аппараты (виды тарелочных и насадочных устройств) и ректификационные колонны (применяемое в них давление: атмосферные, вакуумные, под определенным давлением; и их общее количество). Были рассмотрены прогрессивные схемы, применяемые в современном спиртовом производстве России и за рубежом (Украина, США, Франция, Финляндия). На основе полученных данных, были сформулированы следующие выводы: наиболее результативные виды контактных аппаратов - ситчатые и клапанные тарелки, среди насадок - кольца Рашига, перспективный тип колонн - тарельчатый, наиболее популярная схема работы ректификационной установки - комбинирование работы под давлением и разряжением.

Ключевые слова: спиртовое производство, ректификация спирта, схема ректификационной установки, ректификационная колонна, этиловый спирт, спирт-ректификат, контактные аппараты.

Цитирование. Оганесян Е. А., Колесниченко Ю. В., Срослова Г. А. Прогрессивные схемы и способы получения спирта-ректификата, применяемые в России и за рубежом // Природные системы и ресурсы. 2021. - T. 11, № 2. - С. 66-73. - DOI: https://doi.org/10.15688/nsr.jvolsu.2021.2.8

\section{Введение}

В начале спиртового производства из бражки этилового спирта и содержащихся в ней примесей путем перегонки получают спирт-сырец. Он загрязнен различными по химической природе веществами (альдегидами, эфирами и кислотами), не соответствует требуемым стандартам качества и требует дополнительной очистки путем ректификации [5]. Ректификация - это тепло-массообменный процесс, применяемый для разделения жидких смесей, компоненты которых различаются по температурам кипения. Цель процесса ректификации состоит в освобождении этилового спирта от примесей, то есть в получении спирта-ректификата и достижении его стандартной крепости. По физико-химическим показателям этиловый ректификованный спирт из пищевого сырья должен соответствовать требованиям, приведенным в пункте 4.1.3 ГОСТа 5962-2013.

Процесс ректификации осуществляется в специальных аппаратах - ректификационных колоннах, которые имеют вид высоких вертикальных цилиндрических установок.

\section{Контактные устройства}

Главной частью колонны, где происходит массотеплообмен между противоточно-движущимися неравновесными потоками пара и жидкости являются контактные устройства. Они могут быть представлены тарелочными или насадочными аппаратами. Тарелочные контактные устройства чаще всего изготавливаются из стали и меди, наиболее распространенными и перспективными из которых считаются:

1. Переливные тарелки (см. рис. 1):

a) Колпачковые: работают при изменениях нагрузок по газу и жидкости, но сложны в устройстве, дорогостоящие, трудны в очистке, имеют низкие предельные нагрузки по газу и невысокое гидравлическое сопротивление. Поэтому колонны с колпачковыми тарелками вытесняются более прогрессивными конструкциями тарельчатых аппаратов; 


\section{НОВЫЕ БИОТЕХНОЛОГИИ В АГРОПРОМЫШЛЕННОМ КОМПЛЕКСЕ}

б) ситчатые: простые в монтаже, осмотре и ремонте, имеют небольшое гидравлическое сопротивление, устойчивы в широком диапазоне скоростей пара, но чувствительны к загрязнениям.

в) клапанные: имеют высокую пропускную способность по пару, широкий диапазон гидродинамической устойчивости, постоянную и высокую эффективность, но также повышенное гидравлическое сопротивление, чувствительность к неточностям сборки.

2. Провальные: низкая стоимость и гидравлическое сопротивление, легкость монтажа и обслуживания, высокая производительность, но велика вероятность неточности при разделении, чувствительны к соблюдению режима процесса, работают только при больших скоростях пара, низкоэффективные.

3. Прямоточные: применяются при разделении под давлением. Достоинства: повышенная производительностью и высокая эффективность работы. Недостаток: дороговизна, так как все межтарельчатое пространство заполнено металлом, повышенное гидравлическое сопротивление и трудоемкость изготовления.
Из представленных видов тарелочных аппаратов наиболее целесообразны в использовании тарелки переливного типа с ситчатым и клапанным устройством, а провальные и прямоточные имеют повышенную чувствительность к загрязнениям, менее эффективны в эксплуатации и требуют больших затрат.

В отличие от тарелочных колонн, в насадочных поверхностью контакта является поверхность насадки, выполненная из керамики, фарфора, стали и др. (рис. 2). Выбор материала определяется следующими требованиями: хорошая смачиваемость и равномерное распределение орошающей жидкости; малое гидравлическое сопротивление газовому потоку; возможность высоких нагрузок аппарата; малая плотность; стойкость к агрессивным средам; высокая механическая прочность; невысокая стоимость. При глубоком разделении смеси газов и при проведении абсорбции под повышенным давлением целесообразнее использовать мелкую насадку, так как при этом потеря напора в абсорбере составит малую долю от общего давления газовой смеси. А в случае работы с загрязненными средами применяют регулярные насадки $[2 ; 3]$.
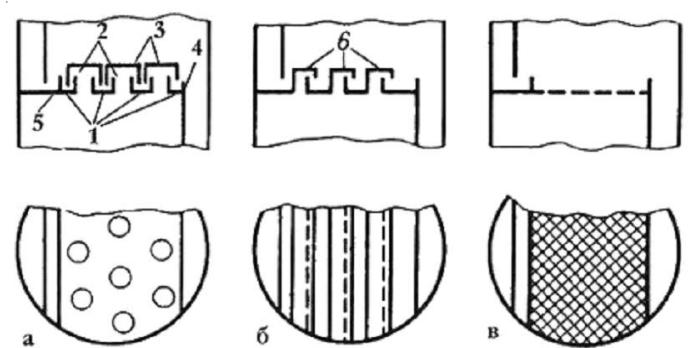

Рис. 1. Переливные тарелки

Buдb: $a$ - колпачковая, $\sigma$ - клапанная, в - ситчатая тарелки.

Структура: 1 - основание со слоем жидкости; 2 - патрубки для прохода пара; 3 - колпачки; 4, 5 - переливные устройства

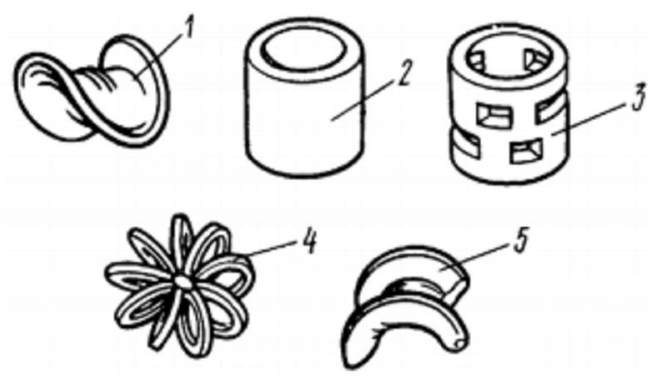

Рис. 2. Формы элементов насадки:

1 - седло Берля; 2 - кольцо Рашига; 3 - кольцо Палля; 4 - розетка Теллера; 5 - седло «Инталокс» 
Насадочные колонны отличаются простотой устройства и низким гидравлическим сопротивлением, но также содержат и ряд недостатков - сложность отвода теплоты, плохая смачиваемость при низких плотностях орошения, большие объемы насадки из-за ее недостаточно высокой эффективности.

Наиболее бюджетным и простым в изготовлении вариантом насадки являются тонкостенные кольца Рашига. Самые дорогостоящие - седлообразные насадки «Инталлокс» и Берля, но именно они образуют максимальную поверхность контакта и минимальное гидравлическое сопротивление.

При ректификации этилового спирта чаще всего применяются тарельчатые колонны, отличающиеся своей невысокой стоимостью единицы объема аппарата, большой контактной поверхностью, минимальной разницей давления на тарелке и широким диапазоном нагрузок.

\section{Модификации ректификационных установок}

Для изготовления ректификационных установок, как правило, применяется медь. В последние годы ректификационные колонны круглые в сечении из специальной нержавеющей стали марок $12 \mathrm{X} 18 \mathrm{H} 10 \mathrm{~T}$ или 08X18Н9Т, а при переработке агрессивных бражек (в гидролизной промышленности) титан [4]. По техническому назначению ректификационные установки классифицируются на сырцовые, установки для ректификации спирта-сырца, брагоректификационные и аппараты для абсолютирования спирта.

Сырцовые установки рассчитаны на производство спирта-сырца. При увеличении числа тарелок в концентрационной колонне такие установки могут использоваться и для получения технического спирта, который применяется в предприятиях органического синтеза и микробиологической отрасли как сырье, а в промышленности как растворитель вводится в моторные топлива для повышения их октанового числа. В США для получения «газохола» (бензин с $10 \%$ спирта) применяют спирт 96-96,2 об. В странах, где отсутствует производство синтетического спирта, технический спирт вырабатывается из низкокачественного крахмалсодержащего сырья [8].
Установки для ректификации спиртасырца направлены на очистку его от примесей и на получение ректификационного спирта. В настоящее время в промышленности применяются только одноколонные сырцовые установки, которые по сравнению с двухколонными проще по устройству и в эксплуатации, менее металлоемки, требуют меньшей рабочей площади, а расходуют примерно на 10 \% меньше пара и воды. По способу очистки спирта-сырца установки подразделяются на непрерывно и периодически действующие. В настоящее время периодически действующие и сырцевые ректификационные установки, из-за их низкой производительности и качества получаемого продукта, заменяются непрерывно действующими брагоперегонными установками [8].

Число колонн в ректификационных установках может варьироваться. Сырцовые установки, чаще всего, одноколонные, брагоректификационные-многоколонные. В США повсеместно используется многоколонные установки, совмещающие в себе ректификационную колонну и кубовый аппарат. Характерная схема брагоректификационной установки для производства ректификованного спирта в США приведена на рисунке 3 . Крепость получаемого дистиллята от 85 до 94 \% об. [4; 9].

В брагоректификационных аппаратах сконцентрированы этапы технологий производства сырцовых установок и установок для ректификации спирта-сырца, что позволяет получать ректификованный спирт напрямую из затраты ресурсов бражки, снижая щ и потери спирта. Такие установки обычно имеют три основных и одну-три дополнительных колонн. От способа присоединения бражной колонны в схему различают установки прямого, непрямого и косвенного действия [1].

На спиртовых заводах стран СНГ в качестве типовых были приняты трехколонные брагоректификационные установки косвенного действия, так как они стабильны в работе, легки в управлении и регулировке, обеспечивают выработку спирта высокого качества, а примеси выводятся в концентрированном виде [8].

В зависимости от применяемого давления в колоннах, ректификационные установки подразделяются на вакуумные (работающие под разрежением), атмосферные и работаю- 


\section{НОВЫЕ БИОТЕХНОЛОГИИ В АГРОПРОМЫШЛЕННОМ КОМПЛЕКСЕ}

щие под избыточным давлением (рис. 4). В спиртовом производстве бывшего СССР, в основном, применялись ректификационные установки, работающие под атмосферным давлением.
В странах СНГ и за рубежом широко распространена практика эксплуатации ректификационных установок, в которых часть колонн работает под разрежением, а остальные под давлением, что позволяет многократно

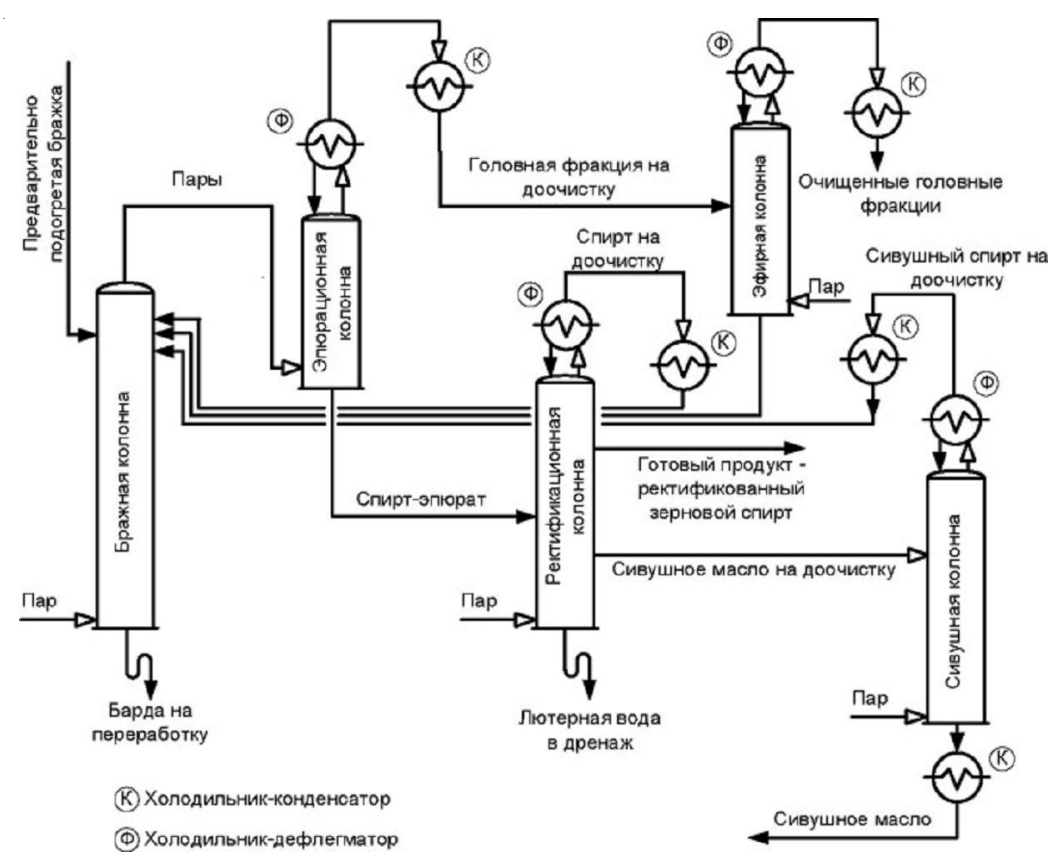

Рис. 3. Пятиколонная браго ректификационная установка

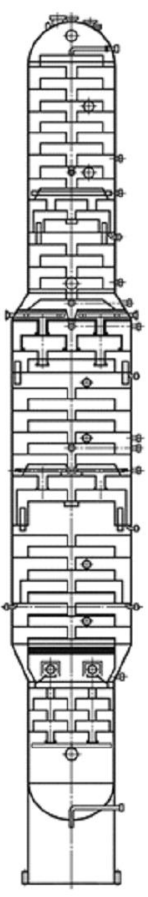

a

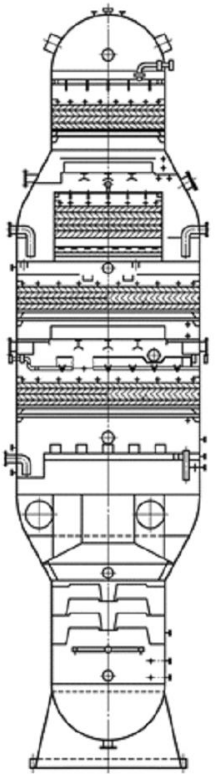

6

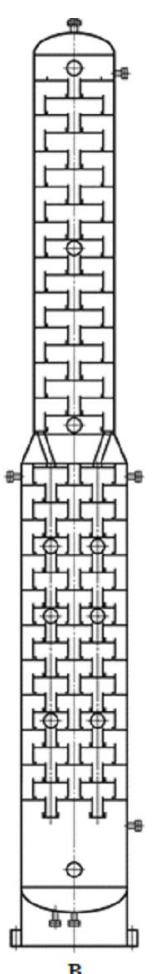

B

Рис. 4. Колонны, работающие под разным давлением:

$a$ - атмосферная; $\sigma$ - вакуумная; в - под давлением (согласно ГОСТ Р 53684-2009, П. 3 ) 
Прогрессивные схемы и способы получения спирта-ректификата, применяемые в России и за рубежом

использовать теплоту при ректификации и снизить энергозатраты.

В большинстве своем, вакуумные брагоректификационные установки конструировались на основе аппаратов косвенного действия по двум вариантам:

а) Бражная установка работает под разрежением, получая тепло от конденсации пара спиртовой колонны - так функционируют установки от фирмы «Спейшим» (Франция), некоторые аппараты в США и установка, разработанная Баранцевым В.И. в Воронежском техническом институте (см. рис. 5, I); b) И наоборот, под разряжением работает уже спиртовая колонна, а тепло идет от бражной колонны - так устроены некоторые аппараты США, установки, разработанные в «УкрНИИ спиртбиопрод» и др. (рис. 5, II) [6].

Киевский технологический институт (КТИПП) представил схему одного из простых вариантов вакуумной установки пищевой промышленности на базе трехколонной брагоректификационной установки косвенного действия, которая экономично расходует пар и воду (рис. 6).
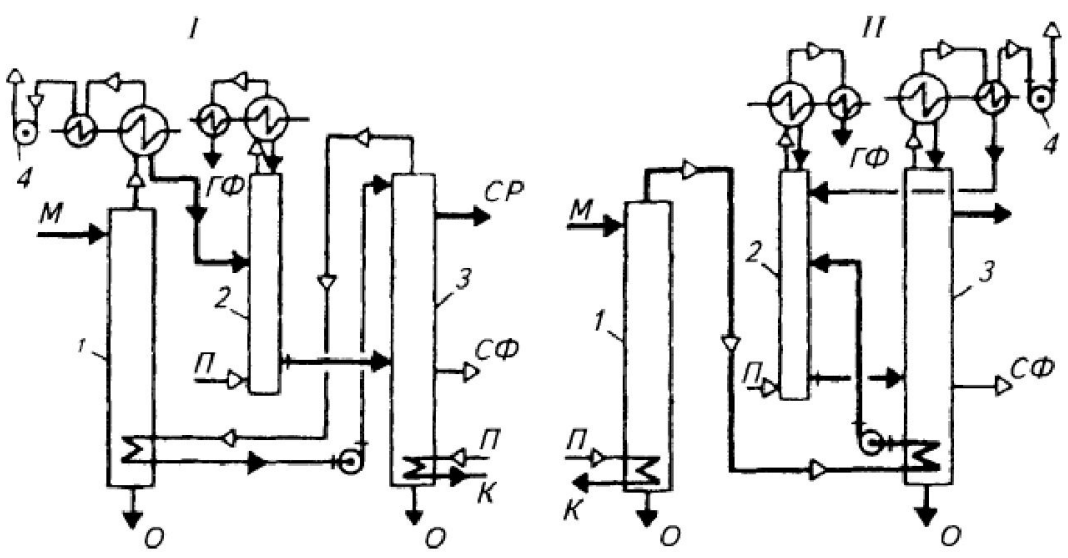

Рис. 5. Схемы вакуумных брегоректификационных установок:

$I$ - под разряжением работает бражная колонна, обогрев осуществляет спиртовая; $I I$ - под разряжением работает спиртовая, обогрев осуществляет бражная.

Колонны: 1 - бражная; 2 - эпюрационная; 3 - спиртовая; 4 - вакуум-насос

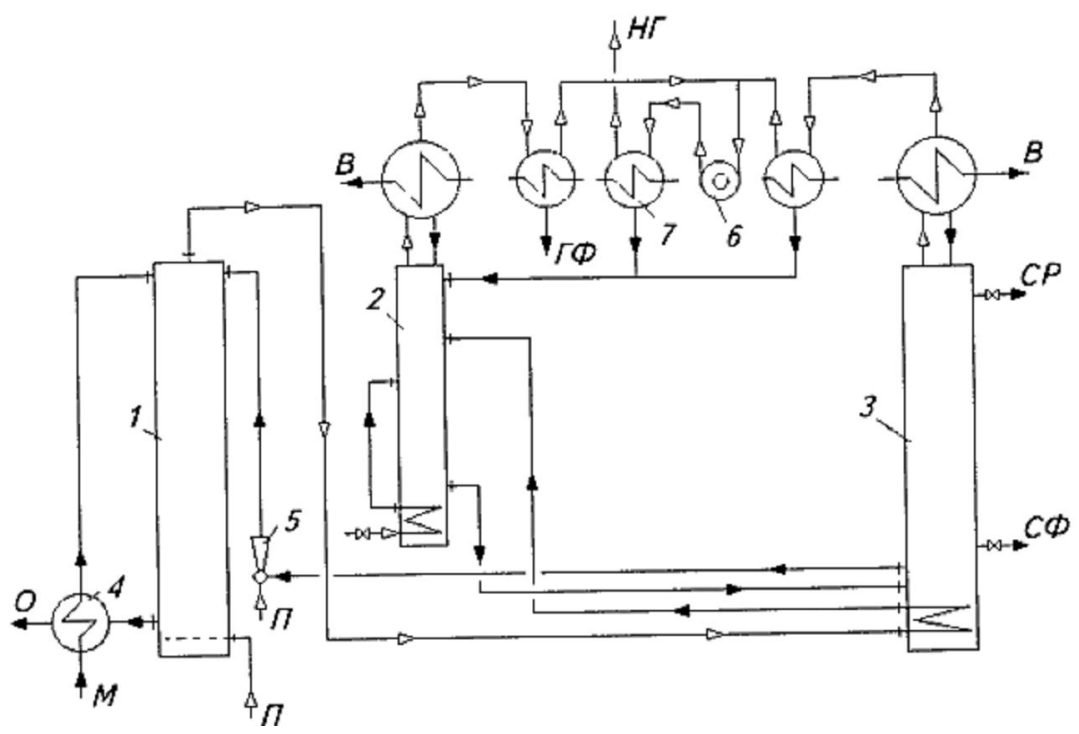

Рис. 6. Схема вакуумной брагоректификационной установки КТИПП. Колонны:

1 - бражная; 2 - эпюрационная; 3 - спиртовая; 4 - подогреватель бражки; 5 - эжектор; 6 - вакуум-насос; 7 - спиртоловушка 
В отличие от схемы КТИПП, Австрийская фирма «Фогельбуш» не применяет вакуума. Здесь используются установки с тремя ступенями давления значением более 150 кПа. Установки финской фирмы «Розенлев» также работают стремя ступенями давления, но последние находятся под вакуумом.

Абсолютный спирт может быть получен из ректификованного спирта или непосредственно из бражки - в любом случае ректификованный спирт и водосвязывающее вещество вводят в дегидратационную колонну с 60-65 многоколпачковых тарелок. В странах СНГ абсолютирование спирта производится методом образования тройных нераздельнокипящих смесей при добавлении к 95-96,5 \% углерод циклогексан и бензол [8].

Абсолютный спирт в небольших количествах применяется в лабораторной промышленности и органическом синтезе. Образовывая устойчивые соединения с бензином, в некоторых стран абсолютный спирт применяется в качестве добавки к топливу [7].

\section{Выводы}

После проведенного информационного исследования были выявлены следующие результаты. Так, самым эффективным видом контактного аппарата являются тарелки переливного с ситчатым и клапанным устройством. Среди насадок самым оптимальными были признаны тонкостенные кольца Рашига. Статус наиболее перспективных в использовании аппаратов при ректификации этилового спирта получил тарельчатый тип колонн благодаря небольшой себестоимости, значительной площади поверхности тарелок и минимальным перепадом давления на них.

Обзор ректификационных устройств в странах ближнего и дальнего зарубежья показал, что наиболее популярной схемой работы является одновременное применение колонн, работающих под давлением и под разряжением, что позволяет уменьшить затраты энергии.

В основном, спиртопроизводящие предприятия имеют схожий механизм ректификации, изменяя лишь некоторые этапы переработки, параметры, объемы и строение установок. Такие изменения продиктованы мно- гими факторами: масштабом предприятия, требуемой крепостью продукта и степенью его очистки и другим.

\section{СПИСОК ЛИТЕРАТУРЫ}

1. Анализ современных схем брагоректификационных установок косвенного действия для получения пищевого ректификованного спирта / Т. Г. Короткова [и др.] // Известия вузов. Пищевая технология. - 2007. - № 5-6. - С. 10-14.

2. Ветошкин, А. Г. Инженерная защита окружающей среды от вредных выбросов : уч. пособие / А. Г. Ветошкин. -2-е изд., испр. и доп. - М. : Инфра-Инженерия, 2019. - 416 с.

3. Ветошкин, А. Г. Процессы и аппараты газоочистки : уч. пособие / А. Г. Ветошкин. - Пенза : Изд-во ПГУ, 2006. - 201 с.

4. Макаров, С. Ю. Основы технологии виски / С. Ю. Макаров. - М. : Пробел, 2011. - 196 с.

5. Машины и аппараты пищевых производств: учебник для вузов. В 3 кн. Кн. 2. Т. 2 / С. Т. Антипов [и др.]. - Минск : БГАТУ, 2008. - 591 с.

6. Поникаров, И. И. Расчеты машин и аппаратов химических производств и нефтегазопереработки (примеры и задачи) : уч. пособие / И. И. Поникаров, С. И. Поникаров, С. В. Рачковский. - М. : Альфа-М, 2008. -720 с.

7. Технология спирта / В. Л. Яровенко [и др.]. М. : Колос : Колос-пресс, $2002-463$ c.

8. Цыганков, С. П. Руководство по ректификации спирта / С. П. Цыганков. - М. : Пищепромиздат, 2001. $-396 \mathrm{c}$.

9. Wilkin, G. D. Raw Materials - Milling, Mashing and Extract Recovery/G. D. Wilkin // Current Development in Malting, Brewing\&Distilling / ed. by F. G. Pries, I. Campbell. - L. : Institute of Brewing, 1983. -P. 35-44.

\section{REFERENCES}

1. Korotkova T.G., et al. Analiz sovremennykh skhem bragorektifikatsionnykh ustanovok kosvennogo deystviya dlya polucheniya pishchevogo rektifikovannogo spirta [Analysis of Modern Schemes of Indirect Distillation Plants for Obtaining Food Rectified Alcohol]. Izvestiya vuzov. Pishchevaya tekhnologiya [Izvestiya vuzov. Food technology], 2007, no. 5-6, pp. 10-14.

2. Vetoshkin A.G. Inzhenernaya zashchita okruzhayushchey sredy ot vrednykh vybrosov: uchebnoye posobiye [Engineering Protection of the Environment from Harmful Emissions: Training Guide]. Moscow, Infra-Engineering Publ., 2019. 416 p. 
Прогрессивные схемы и способы получения спирта-ректификата, применяемые в России и за рубежом

3. Vetoshkin A.G. Protsessy $i$ apparaty gazoochistki: uchebnoye posobiye [Processes and Devices for Gas Cleaning: Training Guide]. Penza, PSU Publishing House, 2006. 201 p.

4. Makarov S.Yu. Osnovy tekhnologii viski [Basics of Whiskey Technology], Moscow, Probel Publ., 2011. 196 p.

5. Antipov S.T. et al. Mashiny $i$ apparaty pishchevykh proizvodstv: uchebnik dlya vuzov [Machines and Devices for Food Production: Textbook for Universities]. Minsk, BSATU Publ., 2008. 591 p.

6. Ponikarov I.I., Ponikarov S.I., Rachkovskiy S.V. Raschety mashin i apparatov khimicheskikh proizvodstv $i$ neftegazopererabotki (primery $i$ zadachi): uchebnoye posobiye [Calculations of Machines and Devices for Chemical Production and Oil and Gas Processing (Examples and Tasks): Training Guide]. Moscow, Alfa-M Publ., 2008. 720 p.

7. Yarovenko V.L., et al. Tekhnologiya spirta [Technology of Alcohol]. Moscow, Kolos, Kolos-press Publ., 2002. 463 p.

8. Tsygankov S.P. Rukovodstvo po rektifikatsii spirta [Guide to Alcohol Rectification], Moscow, Pishchepromizdat Publ., 2001.396 p.

9. Wilkin G.D. Raw Materials - Milling, Mashing and Extract Recovery. Current Development in Malting, Brewing\&Distilling. London, Institute of Brewing, 1983, pp. 35-44.

\section{Information About the Authors}

Helen A. Oganesyan, Student, Department of Biology, Volgograd State University, Prosp. Universitetsky, 100, 400062 Volgograd, Russian Federation, praskovyaa@gmail.com

Iulia V. Kolesnichenko, Student, Department of Biology, Volgograd State University, Prosp. Universitetsky, 100, 400062 Volgograd, Russian Federation, koles209@mail.ru

Galina A. Sroslova, Candidate of Sciences (Biology), Associate Professor, Department of Bioengineering and Bioinformatics, Volgograd State University, Prosp. Universitetsky, 100, 400062 Volgograd, Russian Federation, sroslova.galina@volsu.ru

\section{Информация об авторах}

Елена Ашотовна Оганесян, бакалавр кафедры биологии, Волгоградский государственный университет, просп. Университетский, 100, 400062 г. Волгоград, Российская Федерация, praskovyaa@gmail.com

Юлия Валерьевна Колесниченко, бакалавр кафедры биологии, Волгоградский государственный университет, просп. Университетский, 100, 400062 г. Волгоград, Российская Федерация, koles209@mail.ru

Галина Алексеевна Срослова, кандидат биологических наук, доцент кафедры биоинженерии и биоинформатики, Волгоградский государственный университет, просп. Университетский, 100, 400062 г. Волгоград, Российская Федерация, sroslova.galina@volsu.ru 